\title{
COMPARATIVE STUDY OF ULTRASOUND AND COMPUTED TOMOGRAPHY IN EVALUATION OF BLUNT ABDOMINAL TRAUMA
}

\author{
P. S. L. S Jyothi, V. B. Kalra.
}

1. Post Graduate. Department of Radiodiagnosis, Konaseema Institute of Medical Sciences. Amalapuram.

2. Professor. Department of Radiodiagnosis, Konaseema Institute of Medical Sciences. Amalapuram.

\section{CORRESPONDING AUTHOR:}

Dr. P. S. L. S. Jyothi,

Post Graduate, Department of Radiodiagnosis,

KIMS Medical College,

Amalapuram, Andhra Pradesh.

E-mail: pslsjyothi@gmail.com

ABSTRACT: The objective of our study was to evaluate role of ultrasound and computed tomography in blunt abdominal trauma patients.50 patients with blunt injury to the abdomen were assessed for injuries to various organs using organ injury scale using both USG and CT and the results were compared and the sensitivity and specificity of USG compared with CT was calculated and the positive predictive value and negative predictive value of USG for individual organs was calculated.

The study was performed from August 2012 to February 2013 in the Department of Radiodiagnosis Konaseema Institute of Medical Sciences, Amalapuram, Andhra Pradesh on 50 cases with blunt abdominal trauma.

KEYWORDS: Computed tomography, ultrasound, laceration, contusion

INTRODUCTION: The challenge in the imaging of abdominal trauma is to accurately identify injuries that require early exploration and at the same time avoid unnecessary operative intervention in cases that can be managed conservatively. Blunt trauma in this series, as elsewhere in the world was found to be affecting the relatively younger age group 20$40(68 \%)$ years, much more common in the male population (90\%). A direct abdominal hit or run over accidents are more likely to cause serious internal damage.

Routine USG was done in all patients who were followed by a CT and the time gap between the two examinations as far as possible was tried to be kept to a minimum.

MATERIALS AND METHODS: Fifty cases were studied irrespective of age and sex. In this prospective study patients were selected based on the following:

Inclusion Criteria: All patients with history of blunt abdominal trauma who showed abnormal physical examinations, macroscopic hematuria, unconscious or altered consciousness with suspected abdominal injury. Delayed symptoms like progressive abdominal distention, delayed abdominal pain and tenderness, delayed hematuria and falling vitals.

Exclusion Criteria: Patients in shock, associated spinal injuries, penetrating abdominal injury.

CT Scanning Protocols: Contrast enhanced CT was performed with $50 \mathrm{ml}$ of Intravenous iodinated contrast, $8-10 \mathrm{~mm}$ thick slices were taken from dome of diaphragm to the pubic 
symphysis. Additional thin slice sections were taken where ever required. Early and 5 minutes delay was taken in cases of renal injuries. No oral contrast was given this was avoided since blunt injury abdomen patients were potential candidates for emergency surgery and hence general anesthesia, as opined by the anesthesiologists/surgeons.

All images were viewed in soft tissue as well as lung window settings besides bone window algorithm.

Road traffic accidents (RTAs) are the commonest cause and account for up to

$50 \%$ of trauma related deaths. Abdominal trauma contributes $10 \%$ of overall

mortality and considerably more in terms of morbidity 1 .

The mechanisms of internal injury in blunt injury abdomen are:

1. Direct compression of organs against bony prominences e.g. pancreatic trauma.

2. Structures normally attached to bones via fascia or ligaments getting torn following fracture e.g. urinary bladder trauma.

3. Deceleration injuries e.g. renal trauma.

Prior to advent of CT, the mainstay for radiological evaluation of in blunt injury abdomen were:

1. Plain abdominal radiograph.

2. IVU and nephron-tomogram.

3. Angiography.

4. Radionuclide studies.

5. Ultrasonography.

Danne $\mathrm{PD}^{2}$ stated that the practice of making diagnosis in blunt injury abdomen by repeated clinical examinations over prolonged periods of time is to be condemned and that CT is the best organ imaging technique. His observation that an initial clinical examination may fail to detect many abdominal injuries also found support from Mackersie et.al ${ }^{3}$. Consistent unreliability is observed on clinical examination of pancreatic and retroperitoneal injury, Lang EK et $\mathrm{al}^{4}$.

A.R Padhaniet $\mathrm{al}^{5}$ series of a retrospective analysis of role of CT in blunt injury abdomen these indications for CT were:

1. Abnormal abdominal physical examination.

2. Hematuria.

3. Multiple injuries.

4. Unreliable physical examination due to unconsciousness.

5. Unexplained hypotension.

6. Postoperative evaluation.

7. Abnormal chest/abdominal radiograph.

8. Falling hematocrit.

9. Positive or equivocal peritoneal lavage.

10. Delayed abdominal symptoms.

11. Abnormal ultrasound examinations.

Taylor G.A et $\mathrm{al}^{6}$ indicated that severe neurological injury was an indication for CT but added that neurosigns without signs had a low yield. 
Diagnostic peritoneal lavage (DPL) is a technique, which is being extensively studied in comparison with CT regarding its usefulness as an indicator for open surgery. Conflicting views exists regarding this. DPL involves aspiration as well as washing of the peritoneal cavity with saline and subsequent biochemical and microscopic examinations. Four-quadrant aspiration involves aspiration alone and is an inferior technique compared to DPL. Hawkins et al 7 justifies continued use of DPL since it avoids disruption of patient care that might result in the radiology suite. However DPL increases the incidence of non - therapeutic laparotomies (15.5\%) compared to CT $(0.8 \%)$ according to Meredith J.W. et al ${ }^{8}$. The greatest risk is the delay in time that CT adds to the performance of a needed laparotomy-Shoemaker et al9. Minor complications and false negative are also reported with DPL -Orwigs DS ${ }^{10}$. Kane M. et al ${ }^{11}$ pointed out that a post lavage CT leaves residual fluid or even air which makes a subsequent CT diagnosis difficult. Overall the CT results were inferior during the 1980s but have improved considerably in the 1990s due to accumulation of experience and improvement of equipment. Recent reports suggest complementary roles for both CT and DPL i.e. CT for organ specific identification in the presence of a positive DPL-Baron B.J.12.

A scanning method called focused assessment with sonography for trauma (FAST) was devised with a primary objective of developing a procedure that could detect intraperitoneal fluid and could be used easily, after training for brief periods, by surgeons and emergency medicine physicians with limited experience in ultrasonography. Numerous reports have appeared in which the usefulness of FAST has been studied.

These scans are designed to look for free fluid in the pericardium, perihepatic area, perisplenic region, paracolic gutters \& cul-de-sac. The urinary bladder is filled with saline before or during the scan to allow visualization of the cul-de-sac; solid organs are not evaluated for the evidence of injury- SS Lingawi ${ }^{13}$

Generally, such FAST examinations have been performed to detect free fluid in patients with abdominal trauma, and computed tomography (CT) has been performed to detect parenchymal injuries as well as free fluid. Hemodynamically stable patients with positive or indeterminate FAST results undergo CT scanning. Hemodynamically stable patients with negative FAST results are followed by clinical observation and repeated FAST to confirm the absence of injury because organ injuries are not necessarily accompanied by hemoperitoneum. In hemodynamically unstable patients, a positive FAST result leads to an emergency laparotomy, and an indeterminate FAST result leads to a diagnostic peritoneal lavage (DPL) or a CT scan. Meteorism limits the usefulness of ultrasound according to Ivancev et al ${ }^{14}$.

Inaccuracy of USG in diagnosis of solid organ injuries was shown by Akgur F.M15. However its value in detecting hemoperitoneum was highlighted by Boulanger et al ${ }^{16}$. Liu M et al ${ }^{17}$ reported low accuracy for USG (92.4\%) against CT (96.4\%).

Technique: Intravenous contrast opacification is accepted as it improves resolution of small lesions and some lesions are detected only on CECT according to Bulas et al ${ }^{18}$. Miyakawa et $\mathrm{al}^{19}$ emphasizes the need for NECT prior to CECT since some lesions like high attenuation hematomas were observed to become inconspicuous in CECT. A R Padhani et al ${ }^{5}$ series recommends dynamic study with $50 \mathrm{ml}$ bolus followed by $50-100 \mathrm{ml}$ drip infusion. They also recommended bowel opacification.

While Federle et $\mathrm{al}^{20}$ recommends oral contrast, Clancy T.V et al ${ }^{21}$ found that omission of bowel opacification was not a disadvantage. Padhani et $\mathrm{al}^{22}$ suggested that when examination is concentrated on abdomen the proportion of unsatisfactory studies were much lower. Hence 
there is no place for a 'poorly supervised quick look' at the abdomen following a cranial or thoracic study.

Recent Trends: Brody A.S et $\mathrm{a}^{23}$ reports that ultra fast CT has advantage over conventional CT mainly in the form of reduced respiratory and movement artifacts and improved accessibility for support personnel.

McGehee et $\mathrm{al}^{24}$ in a series where CECT was compared with MRI in blunt injury abdomen reported T2 images were equal to CECT in judgment of extent and conspicuity of lesions where T1 and GRE were judged inferior. They concluded that no significant advantage exists over CT by MRI.

DISCUSSION: Liver Trauma: USG detected 11 cases of liver trauma which were $35 \%$ of all abdominal injuries and $22 \%$ of blunt injury to the abdomen. All the cases that were detected on USG were graded using organ injury scale. There were $9(82 \%)$ cases of Grade I liver injury, $1(9 \%)$ case of grade II liver injury and $1(9 \%)$ with grade III liver injury.

CT had detected 15 cases of abdominal injuries, which was 32\% of injuries detected on CT and $30 \%$ of all the cases of blunt abdominal injuries. The injuries detected on CT were graded, $12(82 \%)$ cases of grade I injury, $1(6 \%)$ case of grade II injury, $1(6 \%)$ case of grade III injury and $1(6 \%)$ case of grade IV injury.

Three cases of hepatic trauma missed on USG were detected on CT. Most of them were grade I injuries and also CT helped in better grading of the lesion as one case which was graded II on USG appeared to be grade III on CT. However most of these patients were managed conservatively which did not significantly alter the final outcome in most of these patients. USG had a Sensitivity of $81.2 \%$ and Specificity $97 \%$ in hepatic injuries.

Splenic Trauma: USG detected 7 cases of splenic trauma, which was $21 \%$ of all abdominal injuries and $22 \%$ of blunt injury to the abdomen. There were $3(42 \%)$ cases of grade I splenic injury, $1(14 \%)$ case of grade II injury and $3(42 \%)$ cases of grade III injury of all splenic injuries detected on USG.

CT scan detected 9 cases of splenic trauma, which was $18 \%$ of all abdominal injuries and $18 \%$ of blunt injury to the abdomen. There were $4(44 \%)$ cases of grade I injury and $5(56 \%)$ cases of grade III injury detected on CT.

USG detected only 7 cases of splenic trauma where CT could detect 9 cases of splenic trauma. Of this one case which was grade I on USG was labeled as grade III on CT. Another case which was grade II on USG was labeled grade of III on CT.USG had sensitivity of 78\%, and specificity of $100 \%$.

Renal Trauma: On USG, 11 cases of renal trauma were detected, which were $35 \%$ of all the abdominal organ injuries and $22 \%$ of all blunt injury to the abdomen. $6(54 \%)$ cases were grade I, $4(36 \%)$ cases were grade III and $1(10 \%)$ case of grade IV injury.

On CT 14 cases of renal trauma were detected, which were $30 \%$ of all the abdominal injuries and $28 \%$ of all the cases of blunt injury to the abdomen. Of the 14 cases that were detected on CT, $8(57 \%)$ cases were of grade I, $4(29 \%)$ cases were of grade III , $2(14 \%)$ cases were of grade IV.CT had detected 3 cases of renal trauma which were missed on USG.

In this study CT detected 14 cases of renal trauma compared to USG which detected only 11 cases. Of the 3 additional cases detected on CT, 2 cases were of grade I and one case of grade IV injury. One case which was graded as grade I on USG was found to be grade III. 
Pancreas: In this study there was one case of pancreatic injury detected on USG which is $3 \%$ of all the abdominal organ injuries and $2 \%$ of blunt injury to the abdomen.

CT also detected only one case of pancreatic trauma which is $2 \%$ of all the abdominal organ injuries and $2 \%$ of blunt injury to the abdomen. Both CT and USG detected only one case of pancreatic injury in the form of pancreatic laceration.

Clinical diagnosis of pancreatic trauma is a difficult problem. Being deep seated pancreatic injury is usually associated with other associated visceral injuries. Traumatic injury to the pancreas needed no surgical intervention and was managed conservatively.

Urinary Bladder Trauma: There was only one case of urinary bladder trauma detected on USG which was $3 \%$ of all organ injuries and $2 \%$ of blunt trauma cases.

CT detected 3 cases of urinary bladder trauma which was $6 \%$ of all the abdominal injuries and $6 \%$ of blunt injury to the abdomen. In this study CT detected 2 cases which were missed on USG .The reason for this could be due to partially filled bladder and also CT cystography was done whenever there was a doubt.

The incidence of urinary bladder trauma was low with $3 \%$ on USG and $6 \%$ on CT could detect one case of rupture which was confirmed on surgery. CT could also help us detect the source of hematuria. USG had sensitivity of $25 \%$ and specificity of $100 \%$.

Bowel Injury: USG detected one case of bowel injury which was 3\% of all the injuries detected and $2 \%$ of total blunt injury cases to the abdomen. CT detected 5 cases of bowel injury which was $11 \%$ of abdominal injuries and $10 \%$ of blunt injury cases. CT diagnosed 4 cases of bowel injury which was missed on USG.

The overall incidence of bowel injuries was 3\% on USG and 11\% on CT of all the organ injuries detected .Small bowel injuries were common than in the colon which coincide with the usual pattern of involvement .USG had sensitivity of $94 \%$ and specificity of $94 \%$.

Hemoperitoneum and Hemo pneumoperitoneum: In our study, there were 31 cases of hemoperitoneum detected on USG and CT which were $62 \%$ of all the blunt trauma cases. Hemoperitoneum was commonly associated with liver, spleen and bowel injuries.

CT diagnosis of hemoperitoneum was highly accurate with an average value of $>30 \mathrm{HU}$. However values below this cannot be taken as absence of hemoperitoneum, since it was seen to exist with a about $14 \mathrm{HU}$ value confirmed by needle aspiration. False negative diagnosis encountered can be explained by late hemorrhage that takes place during the time interval between scan and laparotomy which may run into hours. When associated with pneumoperitoneum, bowel was the main source as in three cases.

Retroperitoneal Hemorrhage: No case of retroperitoneal hemorrhage could be detected on USG. However two cases were detected on CT making it better modality in such cases compared to sonography.

CONCLUSION: CT is a superior diagnostic modality in the diagnosis of abdominal trauma. Hence it is imperative that all USG positive cases should be followed by CT abdomen. Similarly CT must also be performed in symptomatic patients with negative USG scans and in patients with suboptimal USG scans. 


\section{Liver Injury Grading (Mirvis criteria)}

\begin{tabular}{|l|l|}
\hline Grade & \multicolumn{1}{|c|}{ Criteria } \\
\hline I & $\begin{array}{l}\text { Superficial lacerations, subcapsular hematoma }<1 \mathrm{~cm} \text {, Peritoneal hemorrhage or } \\
\text { tracking only. }\end{array}$ \\
\hline II & Lacerations 1-3cm deep, central or subcapsular hematoma 1-3cm \\
\hline III & Lacerations $>3 \mathrm{~cm}$, Subcapsular hematoma or deep, central hematoma $>3 \mathrm{~cm}$. \\
\hline IV & $\begin{array}{l}\text { Lacerations }>10 \mathrm{~cm}, \text { Massive central or subcapsular hematoma }>10 \mathrm{~cm}, \text { Lobar } \\
\text { destruction or devascularisation. }\end{array}$ \\
\hline V & Bilobar destruction (maceration) or devascularisation. \\
\hline
\end{tabular}

Spleen Injury Grading (Mirvis criteria)

\begin{tabular}{|l|l|}
\hline Grade & \multicolumn{1}{|c|}{ Criteria } \\
\hline I & $\begin{array}{l}\text { Capsular avulsion } \\
\text { Superficial laceration }(\mathrm{s})<1 \mathrm{~cm} \\
\text { Subcapsular hematomas }<1 \mathrm{~cm}\end{array}$ \\
\hline II & $\begin{array}{l}\text { Parenchymal laceration(s) } \\
\text { Central or subcapsular hematoma(s) } 1-3 \mathrm{~cm}\end{array}$ \\
\hline III & $\begin{array}{l}\text { Laceration }(\mathrm{s})>3 \mathrm{~cm} \\
\text { Deep central/subcapsular hematoma(s) }>3 \mathrm{~cm}\end{array}$ \\
\hline IV & Fragmentation 3 or more segments.Devascularization . \\
\hline
\end{tabular}

\section{Renal Injury Grading (Sargeant and Marquardts classification modified by Federle)}

\begin{tabular}{|l|l|}
\hline Category I & $\begin{array}{l}\text { Contusions or small cortical lacerations with no } \\
\text { communication to the collecting system 75-85\%. }\end{array}$ \\
\hline Category II & $\begin{array}{l}\text { Communication of laceration with collecting } \\
\text { system and extravasation } 10 \% .\end{array}$ \\
\hline Category III & Shattered kidney or pedicle injury 5\%. \\
\hline Category IV or perinephric & UPJ avulsion or renal pelvis laceration. \\
\hline $\begin{array}{l}\text { Subcapsular of the } \\
\text { hematoma seen in any of } \\
\text { above. }\end{array}$ \\
\hline
\end{tabular}




\section{Intra Abdominal Organ Injury Distribution Detect By USG}

\begin{tabular}{|l|l|l|l|}
\hline Organ & No & $\begin{array}{l}\text { \%Among } \\
\text { Organs }\end{array}$ & $\begin{array}{l}\% \text { in Blunt Injury } \\
\text { Abdomen }\end{array}$ \\
\hline Liver & 11 & $35 \%$ & $22 \%$ \\
\hline Spleen & 7 & $21 \%$ & $14 \%$ \\
\hline Pancreas & 1 & $3 \%$ & $2 \%$ \\
\hline Kidney & 11 & $35 \%$ & $22 \%$ \\
\hline U. Bladder & 1 & $3 \%$ & $2 \%$ \\
\hline Bowel & 1 & $3 \%$ & $2 \%$ \\
\hline $\begin{array}{l}\text { Hemoperitoneum } \\
\text { Pneumoperitoneum }\end{array}$ & 31 & - & $62 \%$ \\
\hline Retro peritoneal hemorrhage & - & - & - \\
\hline Parietal wall hematoma & 1 & - & $2 \%$ \\
\hline
\end{tabular}

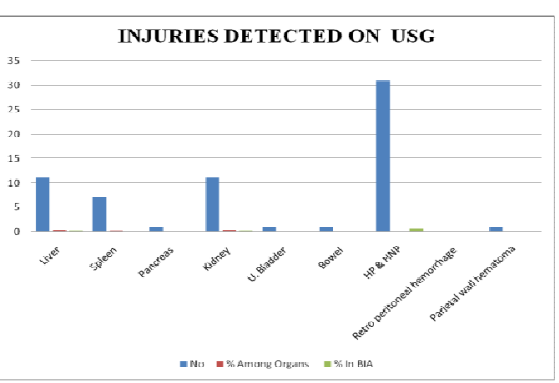

\section{Injuries Detected on CT}

\begin{tabular}{|l|c|c|c|}
\hline \multicolumn{1}{|c|}{ organ } & no & \% among organs & \% in blunt injury abdomen \\
\hline liver & 15 & $32 \%$ & $30 \%$ \\
\hline spleen & 9 & $18 \%$ & $18 \%$ \\
\hline pancreas & 1 & $2 \%$ & $2 \%$ \\
\hline kidney & 14 & $30 \%$ & $28 \%$ \\
\hline U.bladder & 3 & $6 \%$ & $6 \%$ \\
\hline bowel & 5 & $11 \%$ & $10 \%$ \\
\hline pelvic $\neq \neq$ & 3 & 0 & $6 \%$ \\
\hline hp\& hnp & 31 & 0 & $62 \%$ \\
\hline retro peritoneal hematoma & 2 & 0 & $4 \%$ \\
\hline parietal wall hematoma & 1 & 0 & $2 \%$ \\
\hline
\end{tabular}




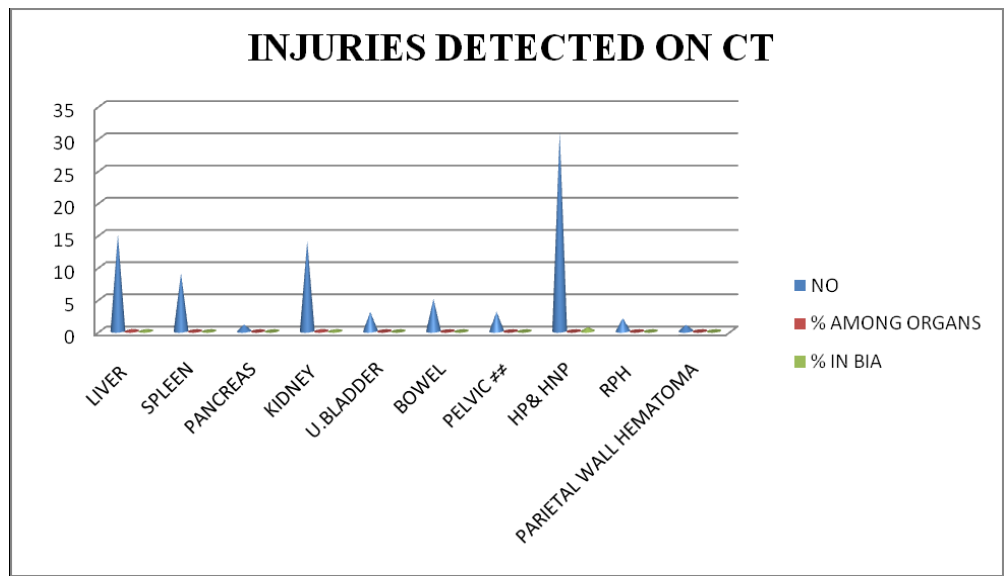

\section{REFERENCES:}

1. Text book of radiology and imaging by David Sutton, Vol1 seventh edition,2003: 691 .

2. Danne P.D. Perspective on early management of abdominal trauma. Australian New Zealand journal of surgery.2000; 112: 511-22.

3. Mackersie RC; Tiwary AD. et al Intraabdominal injury following blunt abdominal trauma. Identifying the high risk. Archives of surgery. 1989; 124: 240-4.

4. Lang EK. Intraabdominal and retroperitoneal injuries diagnosed on dynamic Computed Tomograms obtained for assessment of renal trauma. Journal of Trauma. 1990;30:1161-8.

5. A.R.Padhani C.J.E.; Watson. Et al Computed Tomography in blunt abdominal trauma - an analysis of clinical management and radiological findings. Clinical radiology.1992: 46: 304-10.

6. Taylor G.A.; eich MR. et al Abdominal CT in children with neurological impairment. American Journal of surgery.1989; 210: 229-33.

7. Hawkins ML; Bailey RL. Et al Is diagnostic peritoneal lavage for blunt trauma obsolete? American Journal of Surgery.1990; 56: 96-9.

8. Meredith J.W.; Diteshein JA; Stonehouse S. et al CT and DPL complementary roles in blunt trauma. American Journal of Surgery.1992; 58: 44-8.

9. Shoemaker WC; Corley RD. et al Development and testing of a decision tree for blunt abdominal trauma. Critical Care Medicine.1988; 16: 1199-208.

10. Orwig DS; Jeffrey R.B. et al. CT of false negative peritoneal lavage following blunt trauma. Journal of computed tomography. 1987; 11: 1079-80.

11. Kane M.; Dorfman; Kronan. Et al Efficacy of CT following peritoneal lavage in abdominal trauma. Journal of computed tomography.1987;11: 998-1002.

12. Baron B.J.; Scalea TM; Duncan AO. Et al . Non-operative management of blunt abdominal trauma. Annuals of emergency medicine. 2001; 22:1556-62.

13. SS Lingawi. Focused abdominal sonography in trauma, J HK collRadiol 2001;4: 222-5.

14. Ivancev; Kullendorff. Et al Value of CT in traumatic pancreatitis of children. ActaRadiologica. 1983; 24: 441-4.

15. Agkur F.M.; Tamyel FC; Akhan O. et al. The place of USG examination in initial evaluation of children sustaining blunt abdominal trauma. Journal of Pediatric Surgery. 1993; 28: 7881. 
16. Boulanger; Brennenman FD. Et al A prospective study of abdominal sonography after blunt trauma. Journal of trauma. 1995; 39: 325-30.

17. Liu M.; Lee. CH; Prospective comparison of DPL, CT and USG. Journal of trauma. 1995. 35: 267-70.

18. Bulas; Eichelberger; Sivit; et al. Hepatic injury from blunt trauma in children. American Journal of Radiology. 1993; 160: 251-5.

19. Miyakawa et al. Wakabayashi. Et al CT intestinal injuries following blunt trauma. 1992. 52(12). 653-60. Miyakawa et al. Evaluation of non-contrast enhanced CT on blunt abdominal trauma. 1992; 52: 300-7.

20. Federle MP; Peitzman A. et al Use of oral contrast in abdominal trauma CT scans: Is it dangerous? Journal of trauma. 1995; 38: 51-3.

21. Clancy TV; Ragozzino MW. Et al Oral contrast is not necessary in the evaluation of blunt abdominal trauma by computed tomography. American Journal of Surgery. 1993; 166: 680-4.

22. Padhani et al Computed tomography in blunt abdominal trauma audit of usage and image quality. British Journal of Radiology. 1992; 65: 397-402.

23. Brody AS et al CT evaluation of blunt trauma abdomen in children, comparison of ultra fast and conventional CT. American Journal of Radiology. 1989;153: 803-6.

24. McGehee; Kier.R; Cohn SM.et al Comparison of MRI with post-contrast CT in the evaluation of acute abdominal trauma. Journal of computed tomography. 1993; 17: 410-3.

Figure 1- CECT Abdomen showing non enhancing irregular low attenuation area in segment VIII of right lobe of liver-Laceration. Surrounding haemoperitoneum is seen.

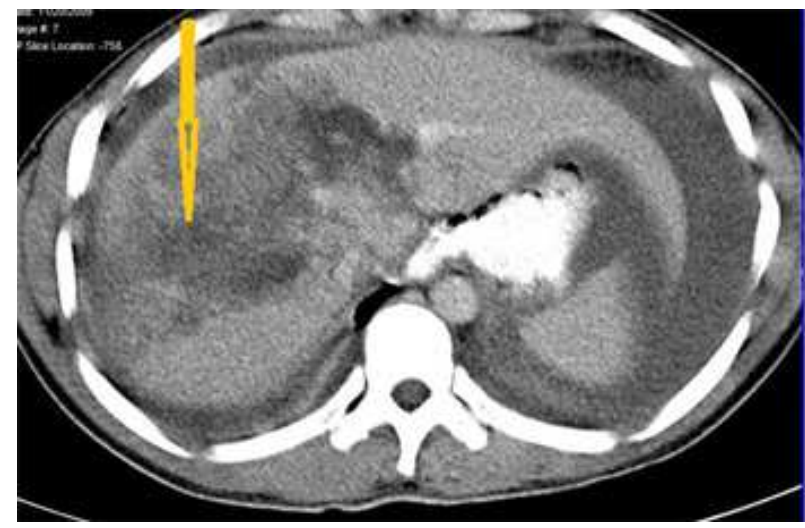




\section{ORIGINAL ARTICLE}

Figure2-CECT abdomen showing hypodense area in spleen suggestive of laceration with perisplenic collection, hemoperitoneum and bilateral haemothorax.

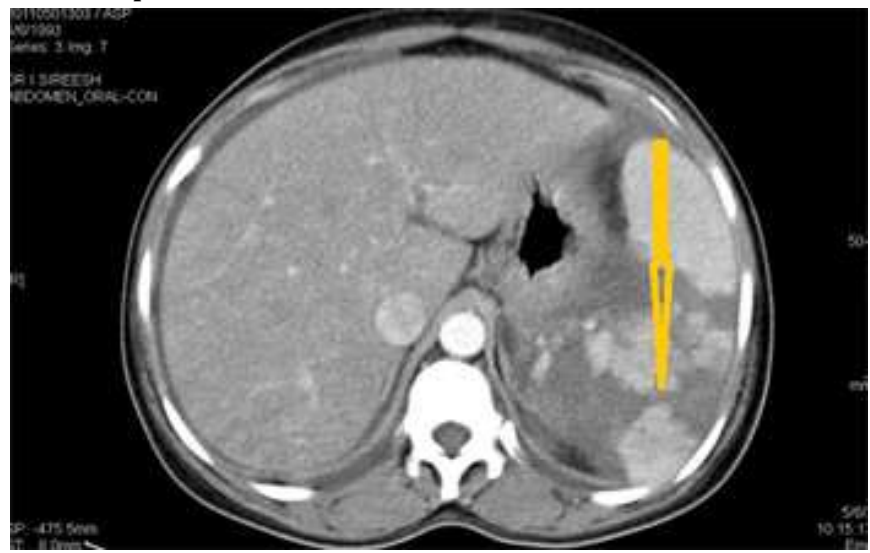

Figure 3- CECT abdomen showing non enhancing hypodense area in spleen suggestive of hematoma with large perisplenic collection and haemoperitoneum.

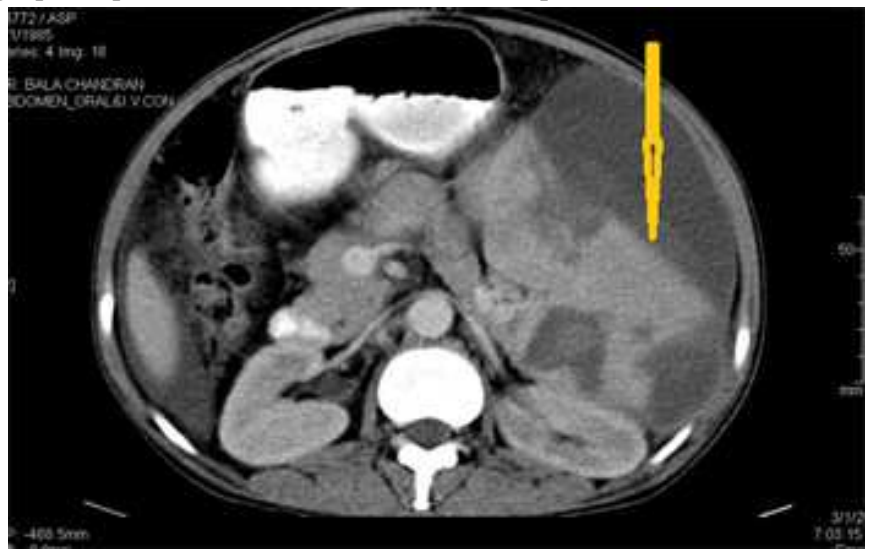

Figure4-CECT abdomen showing non enhancing hypodense area in spleen suggestive of laceration with perisplenic collection and haemoperitoneum.

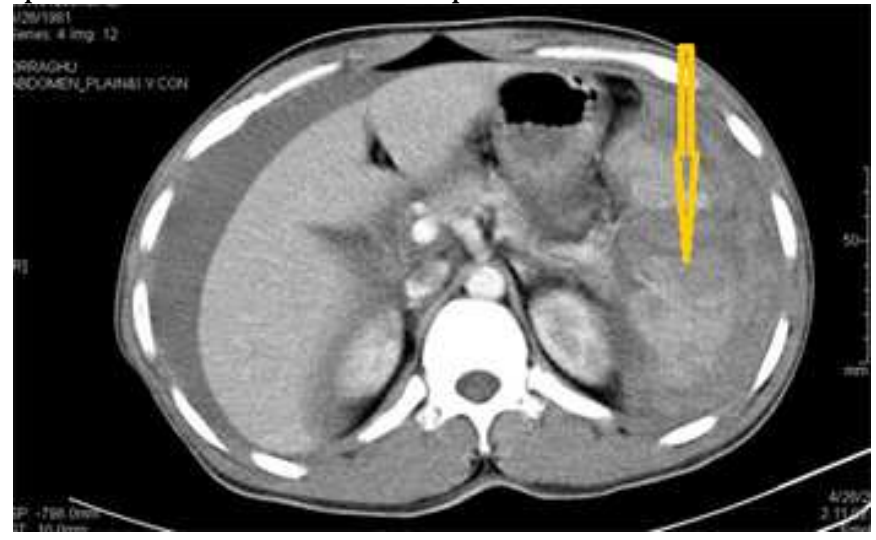




\section{ORIGINAL ARTICLE}

Figure5-CECT abdomen showing non enhancing hypodense area suggestive of laceration in mid polar region of right kidney with perinephric collection.

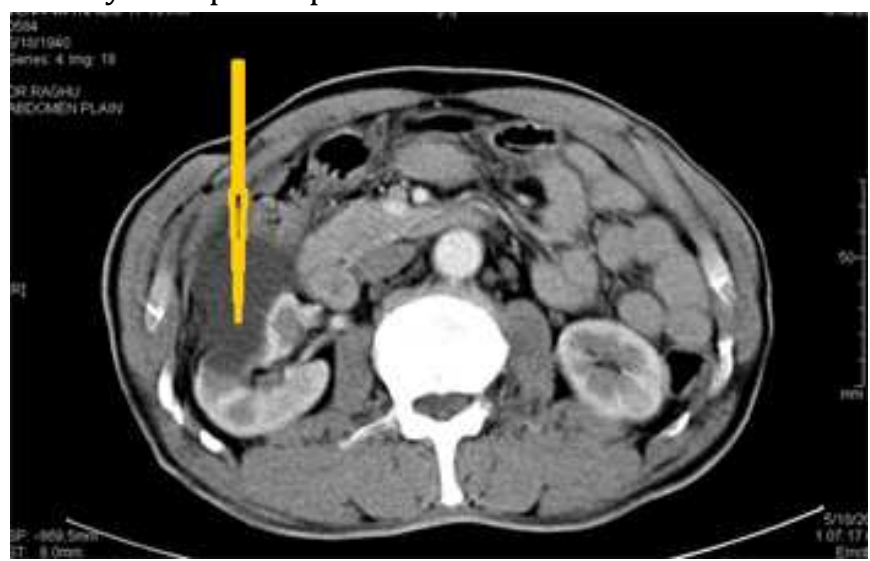

Figure 6- USG abdomen showing hyperechoic area in segment VIII of right lobe of liver suggestive of Laceration

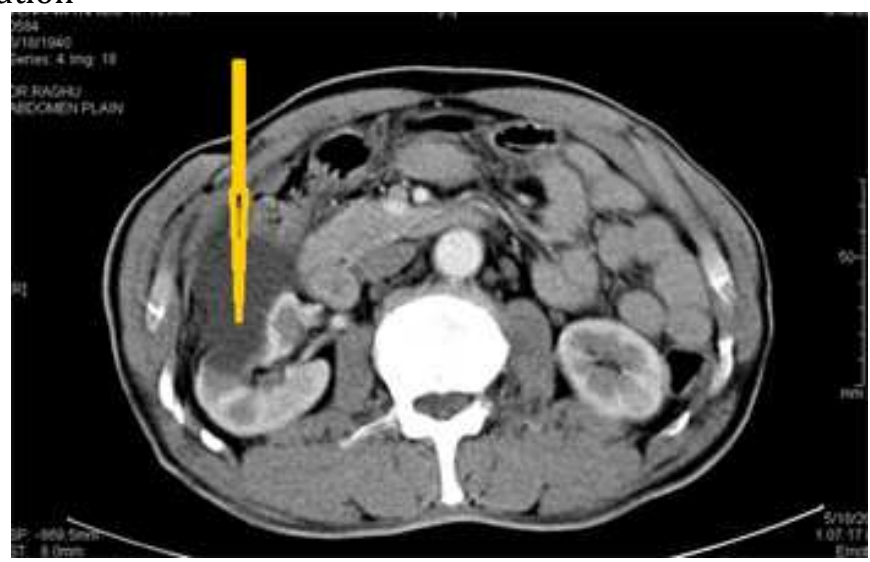

Figure7- USG abdomen showing hypoechoic area in spleen suggestive of laceration, with perisplenic collection.

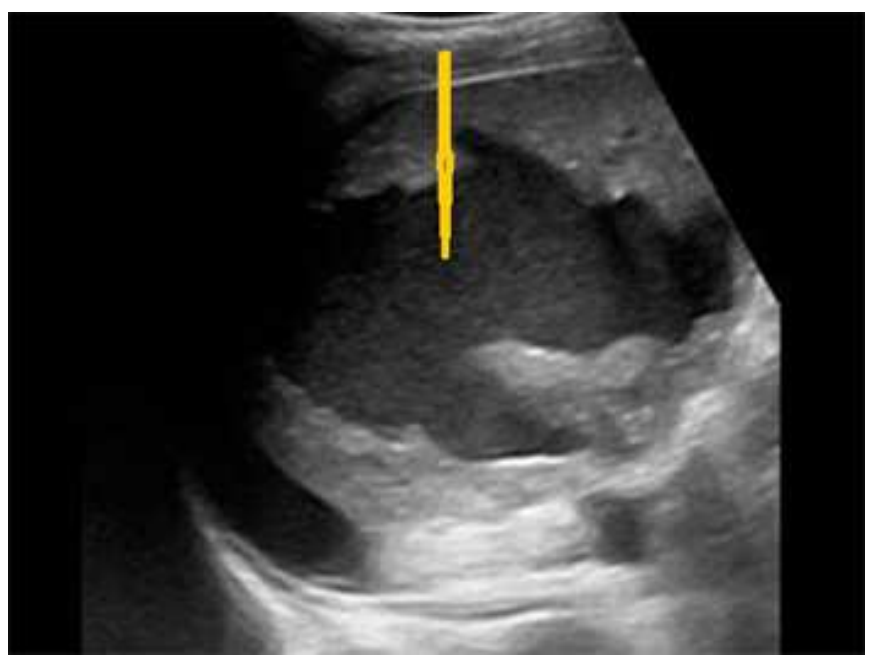




\section{ORIGINAL ARTICLE}

Figure 8 - USG abdomen showing hyperechoic area in upper pole of spleen suggestive of contusion

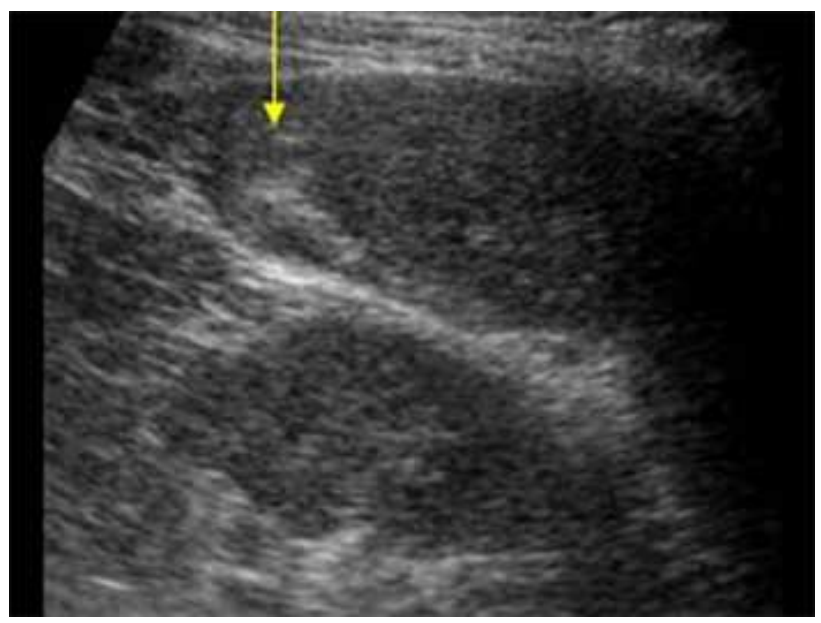

Figure 9 -USG abdomen showing hyperechoic area in upper pole of right kidney suggestive of laceration with perinephric hematoma.

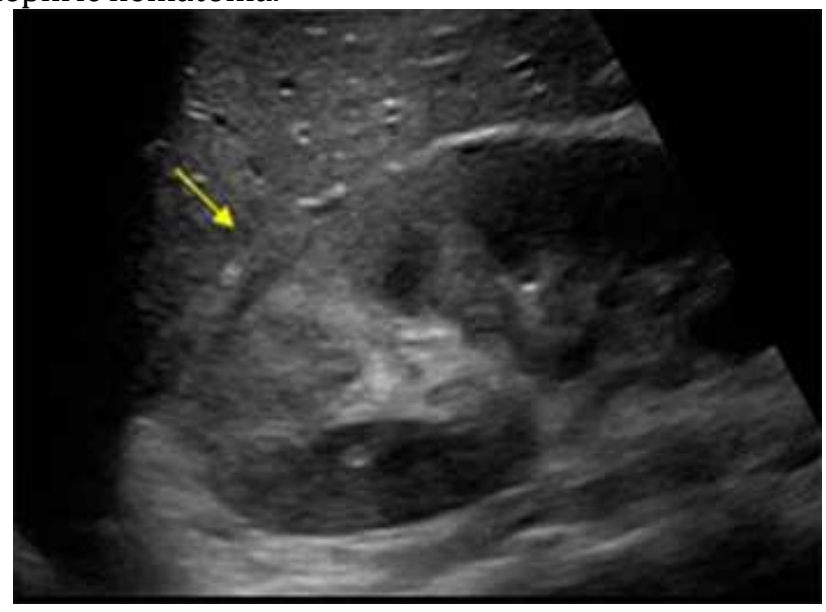

Figure 10 - USG showing fluid (FF) with internal echoes in Morrison's pouch-Haemoperitoneum

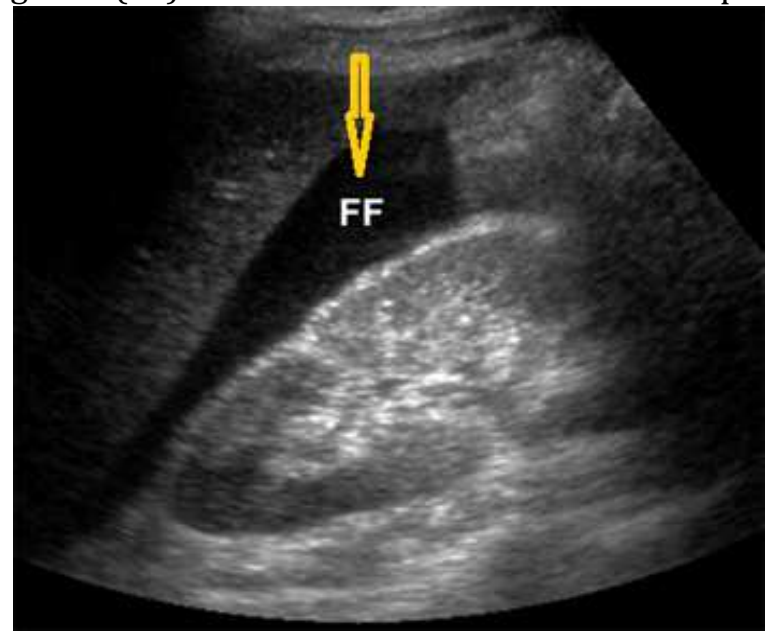

